\title{
Komunikasi Organisasi Antar Budaya di Lembaga Penjaminan Mutu Pendidikan Sumatera Utara
}

\author{
Rudianto, Akhyar Anshori* \\ Program Studi Ilmu Komunikasi, Universitas Muhammadiyah Sumatera Utara, Medan, \\ Indonesia \\ *e-mail: akhyaransori@umsu.ac.id
}

\begin{abstract}
This article is based on the background of the condition of organizational communication at the North Sumatra Education Quality Assurance Agency (LPMP) which involves staff with various cultural backgrounds. In particular, the difference between Civil Servants $(P N S)$ who came from Java and those from North Sumatra. The main objective is to find out the patterns of interaction between civil servants from Java and local civil servants in the LPMP North Sumatra environment. This study was conducted through a qualitative method with an interpretive subjective approach in an effort to explain the phenomenon in depth through data collection by interview and observation. Data analysis in the form of inductive narrative through triangulation techniques. The results of this research found that due to differences in cultural backgrounds, civil servants from Java and local civil servants initially experienced problems in interacting. Civil servants from Java experienced a cultural shock in working at the North Sumatra LPMP because they entered a new place with a new culture from their place of origin. In their interactions, there is no marginalization between civil servants from Java and civil servants from Sumatra. Even though there are differences and conflicts, there is no time for exclusion of a civil servant because of his cultural and ethnic background.
\end{abstract}

Keywords: Organizational Communication, Interaction, intercultural Communication, Cultural Concussion.

\begin{abstract}
ABSTRAK
Artikel ini disajikan atas dasar kondisi komunikasi organisasi di Lembaga Penjaminan Mutu Pendidikan (LPMP) Sumatera Utara yang melibatkan staf dengan berbagai latar belakang budaya, Khususnya perbedaan antara Pegawai Negeri Sipil (PNS) yang berasal dari Jawa dengan yang berasal dari Sumatera Utara. Tujuan utama artikel ini untuk mengetahui pola interaksi antara PNS asal Jawa dengan PNS lokal di lingkungan LPMP Sumatera Utara. Dengan asumsi mereka yang lahir dan menetap lama di Sumatera Utara meskipun berasal dari suku lain di Sumatera Utara, cenderung lebih mudah berinteraksi dengan pegawai lain. Kajian ini dilakukan melalui metode kualitatif dengan pendekatan subyektif interpretatif dalam upaya menjelaskan fenomena dengan sedalam-dalamnya melalui pengumpulan data dengan wawancara dan observasi. Analisis data dalam bentuk naratif induktif. Hasil riset ini menemukan karena perbedaan latar belakang budaya, PNS asal Jawa dan PNS lokal pada awalnya mengalami masalah dalam berinteraksi. PNS asal Jawa mengalami gegar budaya dalam bekerja di LPMP Sumut karena memasuki tempat baru dengan budaya yang baru dari tempat asalnya. PNS asal Jawa dan lokal masingmasing memiliki pemaknaan sendiri-sendiri terhadap sesamanya berdasarkan stereotipe yang selama ini mereka ketahui. Dalam interaksinya, tidak ada peminggiran yang terjadi antara PNS asal Jawa dengan PNS berasal dari Sumatera. Meski terdapat beberapa perbedaan dan konflik, namun tidak sempat terjadi pengucilan terhadap seseorang PNS karena latarbelakang budaya dan suku.
\end{abstract}

Kata kunci : Komunikasi Organisasi, Interaksi, Komunikasi Antar Budaya, Gegar Budaya

Pendahuluan

Lembaga penjaminan mutu Sumut adalah satu dari 33unit pelaksana pendidikan Sumatera Utara atau LPMP teknis di lingkungan Kementerian Pendidikan 
dan Kebudayaan di seluruh Indonesia yang berkedudukan di Sumatera Utara. Lembaga ini bertugas sebagai perpanjangan pusat untuk melakukan penjaminan mutu pendidikan di daerah. Pemilihan LPMP sebagai objek kajian artikel ini lebih dikarenakan LPMP merupakan bagian dari penegakan nilai budaya Indonesia, akan tetapi perbedaan budaya yang terdapat pada para pegawainya, menimbulkan berbagai perbedaan pemahaman dalam interaksi yang terjadi sehari-hari.

Di LPMP Sumut terdapat 126 pegawai dengan status PNS pusat di bawah kendali Kementerian Pendidikan dan Kebudayaan. Para PNS terdiri dari pegawai struktural dan pegawai fungsional/ widyaiswara. Pegawai struktural dibagi menurut 4 seksi/ bidang sedangkan fungsional bergabung dalam kelompok widyaiswara.

Di antara 126 PNS yang ada di LPMP Sumut, terdapat bermacam ragam suku dan latar belakang budaya yang berbeda antara lain Batak, Karo, Minang, Aceh dan Jawa. Suku Batak, Karo, Minang dan Aceh, umumnya mereka yang sudah lama menetap dan bahkan merupakan kelahiran Sumatera Utara. Sedangkan suku Jawa, beberapa di antaranya merupakan asli kelahiran Jawa dan baru menginjakkan kaki ke Medan sejak mereka diterima menjadi pegawai di LPMP Sumut. Sedikitnya terdapat 3 orang PNS yang merupakan kelahiran asli Jawa yang E-ISSN: 2580-6955 kemudian menetap di Sumatera Utara di LPMP Sumut.

Para pegawai yang berasal dari pulau jawa ini, harus mampu dengan cepat untuk dapat beradaptasi dan berinteraksi dengan pegawai dari Sumatera Utara maupun dengan masyarakat di seputar pegawai pendatang itu bermukim. Komunikasi antarbudaya pada dasarnya mengkaji bagaimana budaya berpengaruh terhadap aktivitas komunikasi: apa makna pesan verbal dan nonverbal menurut budaya-budaya bersangkutan, apa yang layak dikomunikasikan, bagaimana cara mengkomunikasikan nya (verbal dan nonverbal) dan kapan mengkomunikasikan nya (Mulyana, 2005). Asumsinya, mereka yang lahir dan menetap lama di Sumatera Utara meskipun berasal dari suku lain di Sumatera Utara, cenderung lebih mudah berinteraksi dengan pegawai lain dan sudah semestinya PNS lokal menerima keberadaan PNS pendatang untuk dapat bersinergi membangun organisasi sehingga tidak terjadi salah persepsi.

Beberapa studi terdahulu yang terkait dengan kajian komunikasi lintas budaya telah di bahas oleh beberapa orang, di antaranya, Lubis (2012a) yang melihat tentang komunikasi antarbudaya etnis Tionghoa dan Pribumi di Kota Medan. Dimana hasil penelitiannya menemukan bahwa agama dan kepercayaan adalah suatu yang hak dan tidak dapat dipisahkan, dalam perjalanannya pernikahan dengan pribumi memberikan Publisher : UMSU Press 
kesepakatan bersama terkait dengan

Rahayuningsih

(2014)

dalam keyakinan yang dimiliki. Dalam kajian penelitiannya tentang komunikasi lintas lainnya, Lubis (2012b) melalui penelitiannya tentang komunikasi antarbudaya Tionghoa dan Pribumi dalam penggunaan bahasa, menemukan bahwa keragaman bahasa di Medan unik, terbuka dan toleran, selama penggunaan bahasa ibu (bahasa daerah) dapat ditempatkan pada tempatnya dan memberikan kenyamanan dalam berinteraksi.

Hasil penelitian lainnya, terkait dengan komunikasi lintas budaya wisatawan asing dan penduduk lokal di Bukit Lawang, Rudianto dkk (2015) menemukan faktor perbedaan budaya, bahasa dan kebiasaan sehari-hari menjadi kendala dalam berinteraksi, baik yang dihadapi oleh wisatawan asing maupun penduduk setempat. Terkait dengan interaksi ini, Martin dan Nakayama (2010) menegaskan terdapat empat cara yang dapat di tempuh, yakni melalui proses asimilasi, separasi, integrasi maupun marjinalisasi. Penyesuaian diri yang dilakukan terhadap lingkungan kerja dan tempat tinggal dengan suasana dan situasi yang baru pastinya akan menimbulkan rasa sensitive, cemas, frustrasi bahkan pertentangan (Thariq \& Anshori, 2017). Matsumoto \& Sung (2011) melihat bahwa kajian terkait dengan perbedaan sikap, nilai, tujuan dan norma dapat bermanfaat bagi pengembangan keilmuan dalam melihat bentuk perbedaan yang ada. budaya dalam organisasi, menemukan bahwa komunikasi lintas budaya tidak dapat dihindari dari perkembangan perekonomian global, dimana pelibatan pegawai atau karyawan yang berasal dari berbagai daerah dan negara, mengharuskan roda organisasi tetap harus berjalan meskipun terdapatnya faktor bahasa sebagai kendala dalam interaksi sehari-hari. Winarti (2017) melalui penelitiannya menegaskan bahwa menambahkan refleksi diri dalam proses memahami interaksi dalam budaya dan bahasa yang berbeda akan menambah nilai diri dalam mengurangi etnosentrisitas.

Melihat kondisi tersebut, peneliti tertarik untuk mengamati bagaimana interaksi yang terjadi antara PNS asal Jawa dengan PNS lain yang merupakan penduduk lokal Sumatera Utara dan hambatan apa saja yang dialami dalam proses interaksi dan sosialisasi dalam sehari-hari.

\section{Metode Penelitian}

Riset ini menggunakan pendekatan subyektif -interpretif. Pendekatan ini bertujuan untuk menjelaskan fenomena dengan sedalam-dalamnya melalui pengumpulan data sedalam-dalamnya. Husserl (1970) menjelaskan faham fenomenologis mencoba untuk memahami budaya melalui pandangan pemilik budaya atau pelakunya. Metode pengumpulan data 
yang digunakan adalah wawancara dan observasi. Responden atau informan dalam penelitian ini adalah PNS asal Jawa dan PNS lokal yang bekerja di LPMP Sumut. Analisis data dilakukan melalui bentuk naratif induktif yaitu dengan cara mengumpulkan keseluruhan data mentah dan menyusunnya berdasarkan kategori-kategori, menjelaskan hubungan-hubungan antara kategori, dan membangun atau menjelaskan teori melalui teknik triangulasi untuk memperoleh hasil yang dapat diandalkan (Moleong, 2000).

\section{Hasil Penelitian dan Pembahasan}

Umumnya para PNS yang berasal dari Pulau Jawa lahir, besar dan menempuh pendidikan dari tingkat dasar hingga perguruan tinggi di Pulau Jawa. Mereka antara lain berasal dari Yogyakarta dan Jawa Tengah. Karena itu, latar belakang budaya Jawa amat melekat erat dalam kebiasaan, adat istiadat dan nilai-nilai yang mereka pakai dalam kehidupan sehari-hari. Karena diterima sebagai PNS di LPMP Sumut, mereka harus menetap mungkin hingga pensiun di kota Medan dan berbaur dengan PNS lain yang berasal dari Sumatera Utara.

\section{Gegar budaya PNS asal Jawa}

Dari hasil wawancara, informan yang merupakan PNS asal Jawa mengaku pada awalnya merasa shock saat baru menetap di Medan. Di kantor mereka merasa tidak nyaman dengan kebiasaan PNS dari Sumatera yang suka berbicara keras dan kasar. OrangE-ISSN: 2580-6955 orang di Medan juga dikenal suka bercanda dan kemudian tertawa terbahak-bahak dengan keras.

Dalam interaksi berkaitan dengan pekerjaan, PNS asal Jawa pada masa tahuntahun pertama bekerja mengalami apa yang disebut gegar budaya. Mereka mengaku seperti terasing berada diantara orang lain yang berbeda budaya. Pengenalan sepintas atau lebih tepatnya prasangka terhadap orang Medan atau batak yang kasar dan keras menjadi gangguan pertama saat mula-mula bekerja di LPMP Sumut. Hal itu membuat mereka agak berhati-hati dan menjaga perilaku dan komunikasi mereka saat bertemu dengan pegawai lain. Sebagai orang yang lahir dan besar di Jawa, mereka tidak banyak mengenal dan berinteraksi dengan orangorang bersuku Batak.

Bahasa meski sama-sama menggunakan Indonesia, namun dialek dan beberapa kosa kata terdapat perbedaan yang terkadang menimbulkan saling tidak paham antara mereka. Gara-gara ketidakpahaman itu, PNS asal Jawa, sering dimarahi pimpinan saat forum rapat karena sering salah memahami pertanyaan dan pernyataan dari atasan. Dahulu, seorang Kepala LPMP sumut yang telah pensiun, jika memarahi anak buahnya akan memaki orang tersebut dengan suara keras di depan orang banyak dengan kata "lateung". Hal ini sempat membuat para PNS asal Jawa terkejut dan ketakutan dengan peristiwa itu. Belakangan, mereka tahu kata 
"lateung" adalah dari bahasa batak yang maksudnya buah terong yang busuk dan tidak berguna. Jadi, orang yang diberi label "lateung" oleh sang Kepala biasanya untuk mereka yang bekerja tidak becus alias melakukan kesalahan. Hal ini sebagaimana hasil penelitian dari Lusiana (2012a) yang menyatakan bahwa keragaman bahasa di Kota Medan menjadikan Medan unik karena bahasa dirasakan bukanlah sesuatu hal yang perlu dijadikan masalah asalkan pihak-pihak yang berkomunikasi tahu menempatkan di mana bahasa daerah (bahasa ibu) tersebut digunakan.

Gegar budaya juga dirasakan karena PNS asal Jawa tidak menemukan suasana yang serupa dengan yang mereka biasa rasakan di kampung mereka di Jawa. Bentuk wajah orang-orang batak yang memiliki rahang persegi yang terkesan tegas, awalnya dianggap oleh mereka yang berasal dari Jawa sebagai orang yang keras dan sombong. Selain itu mereka sering mendapati PNS lokal saling berbicara dengan bahasa batak dengan intonasi yang tinggi. Hal ini menjadikan makna tersendiri bagi mereka yang berasal dari Jawa.

\section{Proses Asimilasi dan Integrasi PNS asal}

\section{Jawa dan PNS Lokal}

Belakangan, setelah melewati masa kerja sekitar 2-3 tahun, PNS asal Jawa mulai terbiasa dengan dialek dan kosa kata Indonesia bergaya Medan. Penggunaan kata kereta misalnya menjadi biasa dipakai untuk menyebutkan sepeda motor bukan "kereta api". Kata kali berarti "sangat atau "amat" berbeda dengan di Jawa yang berarti sungai.

Hal yang sama juga dialami PNS lokal yang awalnya merasa agak asing dengan PNS asal Jawa yang terkesan pendiam dan lambat. Stereotype orang Jawa yang lemah lembut awalnya cukup melekat di benak PNS lokal. Karena itu, terkadang untuk membantu agar PNS asal Jawa keluar dari ketidaknyamanan, terkadang PNS lokal merendahkan intonasi suaranya saat berbicara dengan mereka yang dari Jawa. Menggunakan beberapa kota kata Jawa juga dilakukan untuk menjembatani komunikasi diantara mereka, meski dipakai dengan dialek yang tidak pas. PNS yang bersuku batak biasanya menggunakan kalimat "piye kabare mas" dengan logat batak untuk mengakrabkan diri dengan PNS asal Jawa. Dalam hal bahasa, antara PNS asal Jawa dan lokal, pada masa awal interaksi sempat terjadi gegar budaya. Namun dalam kurun waktu dua tahun, mereka berusaha melakukan penyamaan pemahaman terhadap perilaku berbahasa. Pendatang, dalam hal ini mereka yang dari Jawa memutuskan meninggalkan budaya berbahasa mereka dan berasimilasi dengan bahasa Indonesia dengan dialek dan budaya Medan. Alhasil, kini setelah lebih dari 5 tahun menetap di Medan dan bekerja di LPMP Sumut, PNS asal Jawa sudah menggunakan intonasi suara tinggi ketika berbicara dengan orang lain. 
Begitupun, PNS asal Jawa dan PNS lokal tetap mempertahankan bahasa asli mereka masing-masing saat berkomunikasi dengan sesamanya. Bertemu sesama asal Jawa, maka mereka akan menggunakan bahasa Jawa. Alasannya, mereka lebih nyaman dan merasa dekat dengan budaya kampungnya saat berbahasa Jawa dengan sesamanya. Dalam hal ini, bahasa menjadi representasi kampung halaman mereka. Sama halnya dengan PNS lokal misalnya yang bersuku batak. Mereka tak jarang berbincang dalam bahasa batak jika bertemu dengan sesama orang batak terutama dalam hal-hal yang bersifat informal di kantor.

Untuk urusan pekerjaan, sebenarnya tidak terlalu banyak masalah yang terjadi akibat perbedaan budaya antara mereka yang berasal dari Jawa dengan yang berasal dari Sumatera. Meski demikian, bukan tidak terdapat persoalan karena perbedaan latar budaya tersebut. Biasanya, mereka yang berasal dari Jawa akan lebih terbuka dan lebih dekat dibandingkan dengan mereka yang berasal dari Sumatera. Perasaan sesama perantau dan memiliki kesamaan bahasa dan budaya, membuat PNS asal Jawa lebih nyaman jika secara terbuka membicarakan persoalan-persoalan berkaitan dengan tugastugas dan pekerjaan. Namun karena tuntutan tugas pokok dan fungsi organisasi, harus membuat mereka yang berasal dari Jawa menyebar ke berbagai gugus tugas. Ada yang ditempatkan di Bagian Umum, Seksi Data dan Informasi, Seksi Penjaminan Mutu Pendidikan dan Seksi Pemberdayaan Sumberdaya Pendidikan.

Dengan sistem pembagian tugas dan pekerjaan tersebut, PNS asal Jawa dan lokal harus berintegrasi dalam pekerjaannya meski memiliki latar belakang perbedaan budaya, kebiasaan dan Bahasa. Tak jarang, mereka saling berdiskusi, bepergian bersama dalam rangka pekerjaan dan interaksi lainnya baik di dalam maupun di luar kantor. Suatu ketika, misalnya mereka ditugaskan ke daerah pedalaman di Sumatera Utara dalam kurun waktu 7 hari. Maka mereka harus tinggal dalam satu kamar dan berbaur dalam urusan kebiasaan, bahasa dan makanan. Dengan situasi itu, antara mereka yang berasal dari Jawa dengan yang dari Sumatera, menjadi lebih terintegrasi dalam banyak hal. Perbedaan budaya ini jangan sampai menimbulkan pertikaian berkepanjangan, (Smaldino, 2019) mengutarakan perbedaan identitas sosial yang menyebabkan terciptanya dinamika-dinamika dalam lingkungan seharusnya mampu di mobilisir menjadi kekuatan dalam mewujudkan tujuan bersama. 


\section{Gambar 1. Model Komunikasi Antar Budaya di LPMP Sumut}

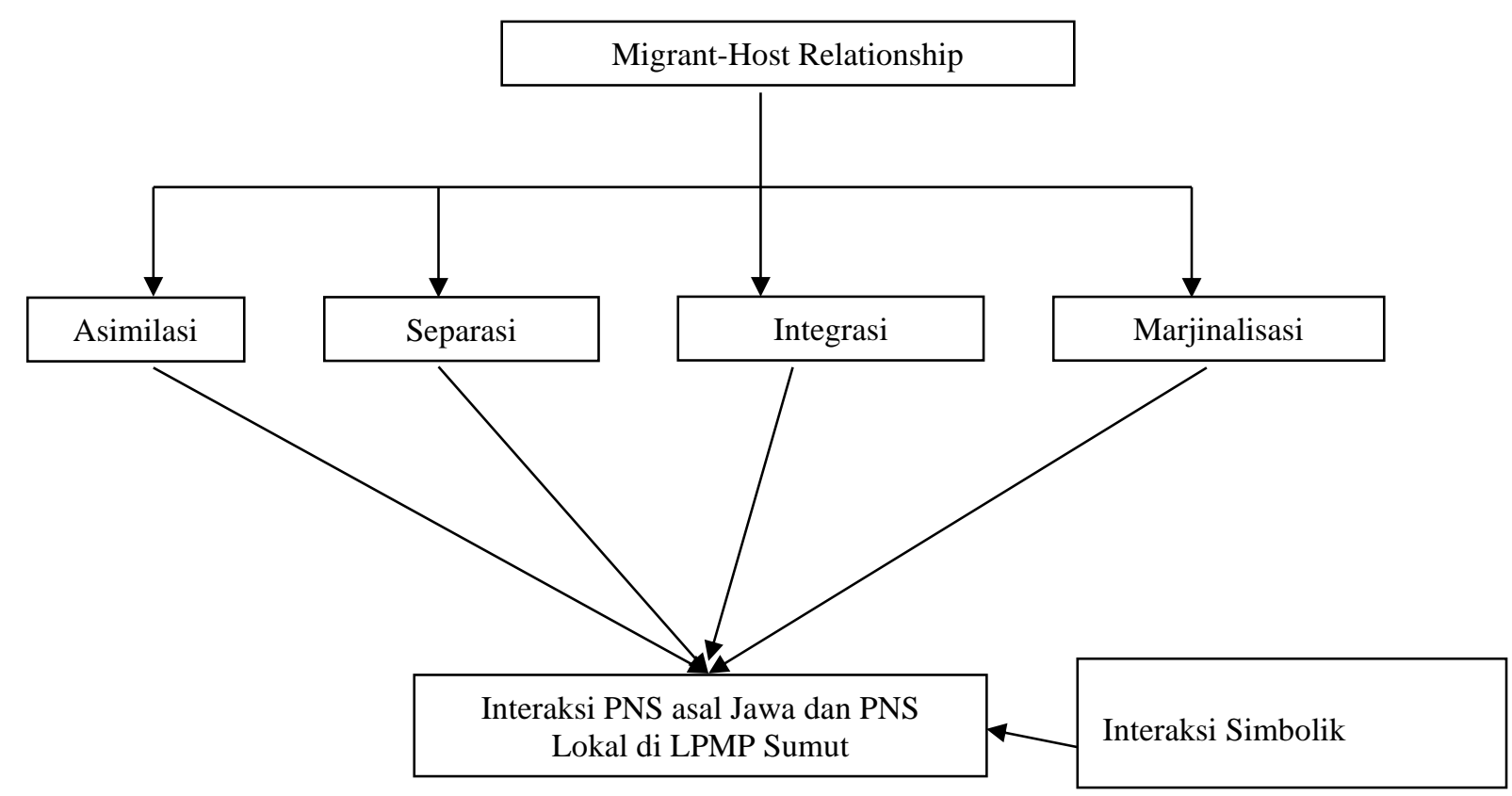

Sumber: Hasil Penelitian

3. Marjinalisasi dan Jarak antara PNS asal Jawa dan Lokal

Meski dalam beberapa hal telah terjadi asimilasi dan integrasi antara PNS asal Jawa dan PNS Lokal, namun tetap saja ada pemisahan untuk situasi tertentu. Saat Kepala LPMP Sumut dipimpin oleh orang yang berasal dari Sumatera Utara, maka orangorang yang dipilih menjadi "ring-1" kepala adalah mereka yang berasal dari Sumatera Utara atau satu suku dengan Kepala. Hal ini diakui oleh para PNS asal Jawa. Saat itu, beberapa pekerjaan penting misalnya bidang keuangan dan umum dipegang oleh mereka yang berasal dari Sumatera. Begitu pula untuk yang menjadi ajudan kepala. Sebaliknya terjadi saat ini ketika Kepala LPMP Sumut berasal dari Jawa Tengah, orang-orang yang berada dekat dengan kepala atau yang memegang pekerjaan penting diisi oleh E-ISSN: 2580-6955 mereka yang berasal dari Jawa. Ketika Kepala LPMP Sumut berasal dari Jawa tengah, maka yang menjadi ajudan dan sekretaris kepala adalah PNS yang berasal dari Jawa. Begitu juga dahulu, saat Kepala LPMP merupakan putra daerah, maka yang menjadi orang kepercayaannya adalah PNS asli Sumatera Utara.

Untuk urusan kekuasan dan pekerjaan penting, kelihatannya perbedaan latar belakang suku dan budaya menjadi alasan untuk terjadinya pemisahan-pemisahan dalam batas-batas tertentu. Setidaknya itu yang dimaknai oleh PNS yang berasal dai Sumatera Utara ketika saat ini, PNS asal Jawa diperankan menjadi ajudan kepala dan beberapa yang lain memegang pekerjaan kunci di kantor. Meski demikian, hal ini dibantah oleh PNS asal Jawa. Mereka mengaku sama sekali tidak memisahkan diri 
berdasarkan budaya untuk pekerjaan yang mereka lalukan. Mereka menilai terjadi kesalahtafsiran dilakukan oleh PNS lokal atas apa yang sedang terjadi. PNS asal lokal cenderung mempertahankan budayanya sebagai tuan rumah dalam berinteraksi dengan PNS asal pulau Jawa. PNS asal Jawa berupaya untuk berasimilasi dan berintegrasi dengan PNS lain yang berasal dari Sumatera Utara agar mereka bisa diterima dan tidak termarginalisasi dalam pekerjaan.

Meski begitu, PNS asal Jawa tidak pernah merasa terkucil kan dengan perbedaan budaya yang ada. Mereka mengaku konflik dan jarak sosial yang terjadi antara mereka dengan PNS lokal lebih bersifat alamiah dan tidak sampai mengganggu pekerjaan. Hal ini seiring dengan apa yang disampaikan Saputra (2019) dalam hasil penelitiannya terkait dengan komunikasi antar budaya mahasiswa di Universitas Islam Negeri Sunan Kalijaga Yogyakarta. Dimana ia menyatakan bahwa hambatan yang berlangsung antara mahasiswa lokal dengan mahasiswa pendatang, tidak lantas menghalangi mereka untuk saling mengenal, mempelajari, beradaptasi dan mengakulturasikan antarbudaya sesama mereka.

\section{Penutup}

Perbedaan latar belakang budaya di LPMP Sumatera Utara antara PNS asal Jawa dan PNS lokal pada awalnya mengalami masalah dalam berinteraksi. PNS asal Jawa mengalami gegar budaya dalam bekerja di LPMP Sumut karena memasuki tempat baru dengan budaya yang baru dari tempat asalnya. PNS asal Jawa dan lokal masing-masing memiliki pemaknaan sendiri-sendiri terhadap sesamanya berdasarkan stereotipe yang selama ini mereka ketahui. PNS asal Jawa dalam beberapa hal melepaskan latar budayanya dan memilih untuk berbaur dengan budaya yang baru. PNS asal Jawa perlahan berasimilasi dengan budaya lokal dalam hal bahasa dan kebiasaan hidup seharihari berkaitan dengan pekerjaan di kantor. Pembagian tugas pokok dan fungsi menurut struktur organisasi, membuat PNS asal Jawa dan lokal berintegrasi dalam menjalankan tugas dan tanggung jawabnya.

Konflik dan jarak antara PNS asal Jawa dan lokal terjadi berkaitan dengan pemusatan pekerjaan penting dan kekuasaan. Saat LPMP Sumut dipimpin Kepala berasal dari Sumut, maka PNS asal Jawa merasa terpinggirkan karena pekerjaan penting dan orang-orang dekat Kepala diambil dari PNS berlatarbelakang suku batak. Demikian juga terjadi sebaliknya. Ketika Kepala LPMP berasal dari Jawa, maka PNS lokal mengesankan pekerjaan penting hanya diprioritaskan bagi PNS asal Jawa. Dalam interaksinya, tidak ada peminggiran yang terjadi antara PNS asal Jawa dengan PNS berasal dari Sumatera. Meski terdapat beberapa perbedaan dan konflik, namun tidak 
sempat terjadi pengucilan terhadap seseorang

PNS karena latarbelakang budaya dan suku.

\section{DAFTAR PUSTAKA}

Husserl, E. (1970). The Idea of Phenomenology (4 (ed.)). Netherlands: Martinus Nijhoff.

Judith N. Martin, T. K. N. (2010). Intercultural Communication in Context (Fifth). McGraw-Hill.

Lubis, L. A. (2012a). Komunikasi Antar Budaya Etnis Tionghoa dan Pribumi di kota Medan. Jurnal Ilmu Komunikasi, 10(1), 13-27.

Lubis, L. A. (2012b). Komunikasi Antarbudaya Tionghoa dan Pribumi dalam Penggunaan Bahasa. Jurnal Ilmu Komunikasi, 10(3), 285-294.

Matsumoto, D., \& Sung, H. (2011). Cooperation and competition in intercultural interactions. International Journal of Intercultural Relations, 35(5), 677-685. https://doi.org/10.1016/j.ijintrel.2011.0 2.017

Moleong, L. J. (2000). Metodologi Penelitian Kualitatif. Bandung: Remaja Rosdakarya.

Mulyana, D. (2005). Komunikasi Efektif Suatu Pendekatan Lintasbudaya. Bandung: Remaja Rosdakarya.
Rahayuningsih, I. (2014). Komunikasi lintas budaya dalam organisasi. Jurnal Psikosains, 9(2), 91-100.

Rudianto, Syam, T., \& Harahap, M. S. (2015). Komunikasi Lintas Budaya Wisatawan Asing dan Penduduk Lokal di Bukit Lawang. Jurnal Simbolika, 1(September), 188-193.

Saputra, E. (2019). Komunikasi Antarbudaya Etnis Lokal Dengan Etnis Pendatang: Studi Kasus Mahasiswa/I Fakultas Adab Dan Ilmu Budaya Uin Sunan Kalijaga Yogyakarta. Interaksi: Jurnal Ilmu Komunikasi, 8(1), 28. https://doi.org/10.14710/interaksi.8.1.2 8-33

Smaldino, P. E. (2019). Social identity and cooperation in cultural evolution. Behavioural Processes, 161(November), 108-116. https://doi.org/10.1016/j.beproc.2017.1 1.015

Thariq, M., \& Anshori, A. (2017). Komunikasi adaptasi mahasiswa indekos. Jurnal Interaksi |, 1(2), 156173.

Winarti, O. (2017). Intercultural Competence in Fostering Teachers' Reflection in Understanding Students' Diversity. Jurnal Studi Komunikasi (Indonesian Journal of Communications Studies), 1(1), $31-45$. https://doi.org/10.25139/jsk.v1i1.65 